I Programa de Pós-Graduação em Sociologia e Antropologia, Universidade Federal do Rio de Janeiro (PPGSA/UFRJ), Brasil josericardoramalho@gmail.com

"I Universidade Federal de Juiz de Fora (UFJF), Brasil santosrodrigosp@hotmail.com

III Universidade Federal Fluminense (UFF), Brasil raphaeljonathas@gmail.com

\title{
ESTRATÉGIAS DE DESENVOLVIMENTO INDUSTRIAL E DINÂMICAS TERRITORIAIS DE CONTESTAÇÃO SOCIAL E CONFRONTO POLÍTICO
}

A lógica das atividades produtivas organizadas em redes de caráter global está, em geral, associada às dinâmicas de um mercado capitalista em busca permanente de novas formas de acumulação. Nessa direção apontam as análises que identificam como resultado desse processo a prevalência dos interesses das empresas independentemente do lugar onde a produção se realiza. A proposta deste texto é questionar esse tipo de interpretação e, através da descrição e exame das ações empresariais de uma rede de produção minero-siderúrgica centralizada na Companhia Siderúrgica Nacional S. A. (CSN), e de seus efeitos sobre os municípios de Volta Redonda (RJ) e Congonhas (MG), ${ }^{1}$ realçar uma perspectiva teórica que reconhece a capacidade de agência de determinados grupos sociais (principalmente sindicatos de trabalhadores, associações de moradores, organizações ambientalistas, igreja, entre outros), para mudar relações de poder e para regular o comportamento empresarial. Os territórios acionados no texto serão considerados a partir da noção exploratória de "arena" (De Sardan, 2005: 185); e os distintos repertórios de ação coletiva de confronto político (Tilly \& Tarrow, 2007; 2008), articulados nas localidades selecionadas, serão analisados de modo a revelar como mecanismos de resistência e defesa da sociedade estão presentes e acabam interferindo na "captura de valor" produzido nesse elo da rede de produção. Nesse sentido, vamos utilizar a proposta teórica construída em torno da expressão "redes globais de produção"2 (Henderson et al., 2011; Santos, 2011) para sus- 
tentar a opção de atribuir força analítica ao papel dos territórios, considerando suas especificidades e sua influência sobre as estratégias corporativas em redes desintegradas geograficamente.

Pretendemos discutir o modo como essa empresa específica, a CSN, reestrutura sua estratégia corporativa a partir do contexto da crise recente do capitalismo em 2008, e interfere diretamente na vida social de Volta Redonda e Congonhas, com ônus em termos de emprego, relações trabalhistas e condições ambientais. E problematizar as reações e articulações locais de contestação social (Hommel \& Godard, 2005) às intenções da empresa, ao criar condições para novas alianças entre diferentes agentes sociais com vistas a enfrentar as ameaças de degradação da vida e dos bens de uso comum.

\section{ESTRATÉGIAS CORPORATIVAS, TERRITÓRIOS E CONTESTAÇÃO SOCIAL}

O peso atribuído às escalas regional, internacional e, principalmente, global, como espaços de decisão e ação econômica e política de grandes empresas, tem limitado o entendimento de que sua constituição efetiva passa pela localidade. Na verdade, o enraizamento territorial (Hess, 2004) da estratégia corporativa é condição essencial da dependência compartilhada - ainda que assimétrica - dos diferentes agentes da reprodução das relações sociais territoriais (Cox \& Mair, 1988: 307). Dessa forma, a escala local, entendida como espaço das relações de poder fundadas na interação cotidiana de múltiplos agentes, se coloca como unidade analítica importante no estudo do condicionamento social da ação econômica.

No entanto, a investigação dos fenômenos economicamente relevantes (Weber, 2000) se relaciona não apenas à multiagência e à interseção das escalas de ação, mas deve ser realizada, também, a partir de um paradigma de relações sociais conflituosas. Este paradigma diz respeito aos recursos empregados por agentes sociais e políticos locais e apreende o território a partir da noção exploratória de "arena" como espaço em que "grupos estratégicos heterogêneos se confrontam, levados por interesses mais ou menos compatíveis (materiais ou simbólicos), com os agentes possuindo diferentes níveis de influência ou poder" (De Sardan, 2005: 186).

A abordagem em termos de "arena" permite uma análise a partir de agências múltiplas, hierárquicas e interativas, tornando imperativo o exame das "estratégias que diferentes categorias de atores empregam" (De Sardan, 2005: 187), assim como possibilita a identificação das variadas formas assumidas pela ação coletiva confrontacional (Tarrow, 2011), ampliando as possibilidades de apurar os conflitos reais dos agentes em interação. Portanto, a defesa de uma análise centrada no território diz respeito, fundamentalmen- 
te, ao entendimento do conflito como núcleo estruturante das relações sociais e da ação coletiva no espaço.

Grupos estratégicos heterogêneos, como empresas e associações patronais, sindicatos de trabalhadores, assim como movimentos e organizações não governamentais ambientalistas, operam recursos econômicos, políticos e sociais diferenciados que se expressam em formas específicas de poder. Desse modo, a tipologia do poder estabelecida na abordagem das "redes globais de produção" (Henderson et al., 2011: 157-159) se aplica às situações analisadas. Enquanto o poder corporativo é definido como a capacidade de um agente econômico de influenciar eficazmente decisões e ações de outros agentes, o poder institucional é exercido por agentes não econômicos variados, incluindo organizações e agências estatais e interestatais. Neste último, o Estado, e suas organizações e instituições em diferentes escalas, desempenham os papéis cruciais na regulação da ação econômica.

Mais importante, o poder coletivo é entendido como a capacidade de influência direta e/ou indireta, política e/ou simbólica, exercida pelos agentes sociais sobre decisões e ações econômicas e políticas. Em realidade, o poder coletivo transcende a política institucional e condiciona as oportunidades e restrições da acumulação de capital.

Os poderes institucional e coletivo fazem referência, assim, ao enraizamento como capacidade de influência das relações sociais lato sensu sobre a ação econômica. ${ }^{3}$ Em particular, o exercício do poder coletivo pode ser apreendido a partir de seus efeitos, isto é, das consequências da contestação social (Hommel \& Godard, 2005: 259). A contestação produz contradiscursos descritivos e explicativos, explicita vínculos entre opções tecnocientíficas e estratégias corporativas, imputa responsabilidades corporativas e institucionais etc., constituindo, essencialmente, uma luta pela legitimidade da ação econômica que se expressa de modo específico em torno de setores e subssetores econômicos.

Considerando a intensidade da exploração de bens naturais promovida pela siderurgia e pela mineração de ferro, ${ }^{4}$ e particularmente, os volumes de matéria-prima, energia e água envolvidos em seus processos extrativos e produtivos, esses setores se encontram particularmente sujeitos à contestação social. Nesse sentido, níveis de ruído e de emissão de efluentes e particulados atmosféricos, de uso de água bruta e reutilização, de controle e disposição de resíduos etc. se encontram permanentemente em disputa, reconstruindo a fronteira entre legalidade e legitimidade. E estudos e relatórios de impacto ambiental, audiências públicas informativas, termos de ajuste de conduta (TACs) e os próprios agentes políticos, como secretarias municipais e estaduais de meio ambiente, tornam-se alvos-chave da contestação.

No exercício do poder coletivo como contestação social, uma variedade ampla de agentes sociais opera ações, rotinas e performances políticas 
confrontacionais (Tilly \& Tarrow, 2007: 16), que vão desde a greve operária (Ramalho \& Carneiro, 2013) até a ocupação e (re)tomada de espaços e bens disputados, mesmo que demonstrativa e temporariamente (Beynon, 1999: 16-17). Na abordagem defendida, originalmente proposta por Charles Tilly (1979; 1978), os repertórios de ação coletiva, dos quais essas ações, rotinas e performances se nutrem, são propriedades relacionais, ou seja, relativas a situações interativas de confronto político (Alonso, 2012; Bringel, 2012). De outro modo, repertórios de ação coletiva não são atribuídos a agentes - ainda que coletivos - mas, fundamentalmente, a estruturas de confronto político.

Por conseguinte, as noções de contestação social como objeção às estratégias de desenvolvimento industrial; de confronto político como forma contestatória agravada manifestada em ações, rotinas e performances públicas; e, de conflito socioambiental como arena ${ }^{5}$ de relações de poder no território, se encontram estreitamente relacionadas com vistas a demonstrar a artificialidade de concepções que pressupõem a liberdade irrestrita das estratégias corporativas do condicionamento social da ação econômica.

Ações, rotinas e performances contestatórias acabam, pois, por interferir nos processos econômicos stricto sensu de criação, ampliação e captura de valor. A adoção da proposta teórico-metodológica construída em torno dos processos contemporâneos de desenvolvimento de "redes globais de produção"6 (Henderson et al., 2011; Santos, 2011) permite justificar a opção de atribuir força analítica ao papel dos territórios, e relacioná-lo às condições concretas de criação, ampliação e captura de valor projetadas por estratégias corporativas.

\section{MERCADO MÍNERO-SIDERÚRGICO E NOVAS ESTRATÉGIAS CORPORATIVAS}

O modo como o mercado mundial de produção de aço e de comercialização de minérios foi reestruturado nos últimos anos nos confere a possibilidade de tomar o caso da CSN em Volta Redonda e Congonhas como um exemplo que pode contribuir para o debate sobre o papel dos territórios, em geral, e dos agentes sociais, em particular, influenciando - ou mesmo condicionando - ações empresariais.

As atividades da rede de produção mínero-siderúrgica global têm apresentado características desafiadoras para quaisquer abordagens teórico-metodológicas unificadas. Se, desde os anos 1970, a indústria siderúrgica reduziu sua participação na transformação industrial (e a demanda por minério de ferro está condicionada a ela), o crescimento econômico dos países que compõem os BRICs, em especial Índia e China, a partir do início dos anos 2000, alterou esse perfil, impactando de forma assimétrica, os nós dessa rede de produção, quanto a preços e volumes, modelos tecnoadministrativos, 
relações de trabalho e padrões socioambientais, além do rearranjo de suas espacialidades extrativas, produtivas e comerciais.

Somadas ao recrudescimento da concentração e centralização de capitais na rede global, essas tendências têm afetado as estratégias corporativas de siderúrgicas operando no Brasil, com o predomínio dos processos de integração vertical à montante - com ênfase na mineração - na elaboração das opções das empresas do setor. Portanto, a reorientação da estratégia corporativa da CSN precisa ser compreendida a partir das dimensões estruturais e conjunturais que caracterizam, na atualidade, o mercado mínero-siderúrgico. A CSN é uma das maiores produtoras de aço do Brasil. Sozinha, sua principal unidade, inaugurada em 1946, a Usina Presidente Vargas (UPV), em Volta Redonda (RJ), possui capacidade produtiva da ordem de 5,6 milhões de toneladas por ano (Mtpa.). ${ }^{8}$ A UPV tem, ainda, o portfólio mais completo e diversificado de aços planos da América Latina. Até então caracterizada por uma atuação essencialmente nacional, a CSN opera, hoje, através de uma rede de produção internacional, com usinas de laminação na Alemanha, nos EUA e em Portugal.

A CSN é controlada pela holding Vicunha Siderurgia S. A., braço siderúrgico do grupo Vicunha S. A., oriundo do setor têxtil e que integrou o consórcio $^{9}$ que a adquiriu em 1993. A mudança na estrutura de propriedade da empresa encerrou uma fase de transformações realizadas na passagem dos anos 1980 para os anos 1990 e que teve como marca a alteração do paradigma produtivo exemplificada pelas metas de redução no número de turnos, de aumento no número de horas trabalhadas e de diminuição no número de funcionários.

Desde a privatização, a empresa intensificou sua estratégia de integração vertical e ingressou no setor de infraestrutura através do controle sobre companhias ferroviárias, energéticas e operadores portuários, entre outras. E, por fim, promoveu o deslocamento dos seus investimentos para a mineração, convertendo a mina Casa de Pedra, assim como o município de Congonhas, ${ }^{10}$ em elemento essencial de sua estratégia empresarial. Isto significa que o processo de integração em rede do grupo pode representar, predominantemente, a mudança de seu foco principal da siderurgia à mineração de ferro. A Nacional Minérios S. A. (NAMISA), empresa controlada pela CSN, ${ }^{11}$ constituiria um primeiro passo da referida reorientação, tendo sido criada com vistas à compra de minério de ferro de produtoras júnior para exportação (CADE, 2008: 1-2). Estima-se que a NAMISA constituirá brevemente a principal plataforma de exportação de minério de ferro da CSN.

Em resumo, a análise deste processo de fragmentação geográfica com integração funcional de infraestruturas produtivas e logísticas, operadas em rede, assim como do modelo mais geral da composição orgânica do capital neste segmento produtivo, pode dar pistas para a compreensão das possibi- 
lidades e limites da ação econômica e, por sua vez, das condições nas quais se opera a reação dos agentes sociais e políticos, que operam predominantemente a partir da escala local.

\section{A PRESENÇA TERRITORIAL DA EMPRESA-VOLTA REDONDA E CONGONHAS}

O município de Volta Redonda (RJ) foi geograficamente constituído ao redor da CSN e viveu, ao longo das últimas décadas, em função de suas decisões. O princípio de disciplinar a força de trabalho e separar objetivamente classes sociais através de uma hierarquização manifestada nos tipos de habitação e nos locais de moradia, na regulação da ação sindical e da vida social dos funcionários em clubes e atividades recreativas (Morel, 1989)12 levou ao predomínio de laços verticais mais fortes do que outras conexões estabelecidas entre os vários agentes locais. A hegemonia da empresa lhe permitiu influenciar a emancipação do município de Volta Redonda e os governos municipais que a seguiram. Mesmo no período em que foi Área de Segurança Nacional, depois do golpe militar de 1964, a CSN manteve seu poder na vida política local, estratégia que permaneceu mesmo após a privatização. Porém, o crescimento da cidade e da economia local, o fortalecimento do Sindicato dos Metalúrgicos do Sul Fluminense (SMSF), bem como a eficácia do trabalho pastoral da Igreja Católica ajudaram a revelar um caráter contraditório do relacionamento da empresa com a cidade, especialmente a partir dos anos 1980, quando grupos, associações de interesse e movimentos sociais se articularam "segundo critérios de menor subserviência à Companhia e unidos por laços cada vez mais horizontais” (Lima, 2010:207-208).

A resistência das organizações da sociedade civil de Volta Redonda, em conjunto com a Central Única dos Trabalhadores (CUT), não foi suficiente para impedir a privatização da CSN em 1993. Em 1997, já com o Grupo Vicunha à frente do Conselho Diretor, acelerou-se a racionalização da gestão da empresa, iniciando-se uma redefinição das bases de seu relacionamento com a cidade, por exemplo, através da desestruturação do polo metal-mecânico regional, composto por pequenas e médias empresas fornecedoras de peças, além de fundições e metalúrgicas locais dedicadas à manutenção de equipamentos da CSN. Isto resultou em cortes dos quase três mil empregos diretos gerados pelas empresas, e desencadeou uma crise na cidade que sedimentou as bases de um ciclo de contestação social.

O distanciamento da CSN com relação à cidade de Volta Redonda se acentuou nos anos seguintes à privatização e, em 2004, escolas e hospitais, símbolos de uma época de paternalismo estatal, foram vendidos; clubes e espaços públicos utilizados pela população foram fechados; e programas sociais foram reduzidos a ações pontuais da Fundação CSN (Braga, 2002). 
Esse conjunto de medidas contra a cidade, e a importância da exportação de minério de ferro, indicam um deslocamento da centralidade dos seus negócios de Volta Redonda para Congonhas. Desde que teve a sua mina Casa de Pedra nacionalizada e incorporada pela CSN, em 1944, Congonhas não havia conhecido tamanha expansão econômica como nos últimos oito anos. Sua arrecadação, por exemplo, saltou de R 4 milhões para R 24 milhões ao ano. ${ }^{13} \mathrm{~A}$ ampliação das atividades de mineração, no entanto, não impediu avaliações críticas sobre a correlação problemática entre a elevação da arrecadação e a melhoria dos indicadores sociais (em especial de educação e saúde) no município (Milanez, 2011), mesmo com os efeitos positivos da abertura de novos postos de trabalho. Estima-se que dos seus 45 mil habitantes, cerca de 10 mil exercem atividades profissionais relacionadas a este setor. É a empresa que mais emprega no município, concentrando $64 \%$ dos empregos gerados na mineração.

\section{CONTESTAÇÃO E CONFRONTO ÀS ESTRATÉGIAS EMPRESARIAIS}

Em Volta Redonda, após a privatização da CSN, a cidade testemunhou o surgimento de um novo conjunto de mobilizações decididas a reverter os efeitos negativos produzidos pelas novas estratégias empresariais. Esse contexto de reestruturação e de integração competitiva de agentes econômicos globalizados estimulou a criação de mecanismos de participação dos agentes locais no espaço territorial e, além de transformar as disputas da arena política, permitiu também a formulação de formas inovadoras de ação coletiva de contestação social e confronto político.

O corte de mais de 12 mil postos de trabalho realizado pela empresa e o consequente esvaziamento econômico da cidade impulsionaram várias manifestações de sindicatos, movimentos sociais e mesmo empresários em busca de alternativas para enfrentar o que descreviam como uma conjuntura de desagregação da comunidade local, de responsabilidade da empresa. 0 Movimento Vamos Repensar Volta Redonda ${ }^{14}$ não conseguiu uma ampla adesão da sociedade civil e, em 1998, as principais entidades de representação do movimento popular da cidade, como o sindicato dos metalúrgicos, a Central Única dos Trabalhadores (CUT), o Sindicato dos Profissionais da Educação (SEPE), o Sindicato dos Trabalhadores da Construção Civil, as Comunidades Eclesiais de Base (CEBs), as pastorais operária e da juventude e o Conselho das Associações de Moradores (CONAM) criaram o movimento Grita Volta Redonda, Pela Dignidade e Pela Vida. Demandando do Governo Federal medidas que reduzissem os efeitos negativos da privatização sobre os trabalhadores, o movimento teve um caráter efêmero na cidade, mas projetou lideranças e articulou mobilizações na arena política local, cabendo destacar o 
Movimento Ética na Política de Volta Redonda (MEP-VR), principal expressão política da Igreja Católica local, nos últimos anos.

No final de 2008, quando a CSN anunciou novas dispensas em sua unidade em Volta Redonda, uma renovada mobilização conseguiu reunir os mesmos agentes econômicos, políticos e sociais até aquele momento incapazes de discutir estratégias unificadas de ação coletiva, para buscar soluções para o desemprego - inclusive com o auxílio de instâncias da administração pública estadual e federal. Embora não tenha sido a primeira experiência de reação aos revezes produzidos por crises econômicas sobre o grande contingente de trabalhadores formado com a industrialização, essa iniciativa, denominada Fórum Demissão Zero (ver Ramalho, 2012), além de questionar as demissões em massa, acabou por associar a questão do desemprego a uma pauta econômica mais ampla, discutindo outras preocupações e estratégias, e fazendo emergir demandas envolvendo empresários médios e pequenos, da indústria e do comércio, e o poder público local. Podemos dizer que teve como mérito ajudar a configurar no território uma mudança na estrutura de oportunidades políticas ${ }^{15}$ (Tarrow, 2009) com um relativo reforço do poder institucional e, principalmente, do poder coletivo no sentido da contestação social das estratégias corporativas.

O papel mais importante de contestação à ação da CSN coube aos representantes dos trabalhadores, através do SMSF. Embora se defrontando com uma realidade sindical alterada pela implantação de relações de trabalho flexíveis no elo regional de redes de produção automobilísticas e siderúrgicas e por novos desafios de representação, tendo em vista o crescimento e diversificação do operariado industrial no Sul Fluminense (Ramalho, 2005), pode-se dizer que o SMSF, apesar das sucessivas crises políticas internas das duas últimas décadas, ${ }^{16}$ preservou recursos políticos obtidos nas greves e nas práticas de negociação com a CSN, permitindo assegurar a legitimidade de seus pleitos.

A motivação política para a existência do Fórum teve um importante componente moral, acionado pela Igreja Católica, ao condenar a injustiça das demissões diante de uma crise de responsabilidade exclusiva dos agentes econômicos e políticos. A mobilização da Igreja confirmou também sua aliança histórica com o SMSF, consolidada em outros momentos de conflito com a CSN, como nos momentos dramáticos do confronto entre CSN/militares com operários em greve em 1988, resultando na morte de três trabalhadores dentro da fábrica (ver Costa et al., 2001). Sempre atenta às questões de direitos humanos e políticos relacionados aos trabalhadores, a ação pastoral dessa Igreja também foi exercida de forma consistente na organização da sociedade civil em demandas associadas aos problemas de moradia, saúde, segurança e meio ambiente e, mais recentemente, se articulou, através do MEP-VR, para fiscalizar a atuação do poder público. A Igreja também se insurgiu con- 
tra atitudes autoritárias por parte da CSN, tanto no período da ditadura militar como no contexto pós-privatização. A proximidade com os representantes dos operários no contexto da crise de 2008/2009 reforçou esse compromisso, estabelecendo uma liderança compartilhada nas principais iniciativas do Fórum Demissão Zero.

Em 2009, com a reativação da economia e a retomada dos empregos nas empresas instaladas na região, houve um decréscimo das atividades políticas do Fórum. Contudo, seu caso tornou-se exemplar como forma de aprofundar a compreensão acerca de experiências regionais de ação coletiva e de conflito entre agentes sociais diversos, em contextos de localidades dependentes de grandes empresas. Mesmo em ritmo lento, provocou uma avanço na pauta de debates, com a incorporação de outras demandas sociais e a intensificação das discussões relacionadas ao meio ambiente, sobretudo no que condiz à poluição causada pela atividade siderúrgica.

O principal desdobramento das atividades do Fórum Demissão Zero foi a constituição e consolidação da Comissão Ambiental Sul, que assumiu um protagonismo na contestação social às estratégias empresariais da CSN. O perfil e a elaboração crítica dos seus principais articuladores repetem de certa forma as preocupações anteriores de movimentos sociais locais, mas incorpora e alarga, através da temática ambiental, um campo de lutas sociais e de ação coletiva de resistência às políticas e atitudes da empresa, e de órgãos do Estado (Leite Lopes, 2004; Beynon, 1999), no tocante às necessidades de preservação de direitos de cidadania.

Apesar de ganhar mais visibilidade e destaque na última década, a questão ambiental surgiu em Volta Redonda, em 1992, no debate sobre os termos do edital de privatização da CSN - destacando-se o engajamento da gestão pública ${ }^{17}$ na introdução de um Programa Ambiental Compensatório (PAC) no município (Lima, 2010). Essa inclusão estabeleceu uma agenda mais ampla de questões relacionadas à qualidade de vida: saúde, saneamento básico, educação, meio ambiente, habitação, transporte coletivo e lazer ganharam proeminência na pauta municipal. No entanto, os principais resultados da ampliação do tema ambiental na cidade foram a renovação do planejamento urbano e a constituição do Programa da Agenda 21. ${ }^{18}$

Em 2003 ocorreu um contencioso ambiental relacionado à situação do condomínio Volta Grande IV - construído pelo SMSF para os metalúrgicos no início da década de 1990 -, que envolveu os movimentos sociais, a Igreja (através da emblemática figura do Bispo Emérito Dom Waldyr Calheiros) e a Prefeitura, em oposição à CSN. No que, possivelmente, foi o maior desastre ambiental da história recente de Volta Redonda, discutiu-se a remoção e a indenização de cerca de 100 famílias de um conjunto habitacional com 750 residências, construídas em uma área cedida pela CSN, que já tinha servido como depósito de resíduos industriais oriundos da produção de aço da Usina 
Presidente Vargas. A concentração desses produtos, considerados de alto teor cancerígeno, seria a razão de haver uma grande incidência de casos de leucopenia e câncer entre os moradores do bairro, além de explicar a série de danos estruturais (rachadura de paredes e lajes) causados em quarenta casas desde que o condomínio foi inaugurado, em 1994. O Ministério Público Estadual (MPE) foi acionado e solicitou a responsabilização da CSN pelo ocorrido.

A ascensão da Comissão Ambiental Sul, nos últimos anos, e a condição pública alcançada pela questão do bairro Volta Grande IV, revelaram para a cidade os impactos socioambientais das atividades desse agente econômico, no caso a CSN, e a atitude de descompromisso por parte da empresa. O que esta Comissão traz de novidade é a liderança de profissionais de classe média (engenheiros e técnicos), além da participação da Igreja Católica, renovada por uma perspectiva de crítica às condições de vida dos trabalhadores da cidade e da região.

Lá no bairro Volta Grande IV, as reuniões eram feitas na comunidade, na igreja lá do bairro. A gente chamava, a Igreja chamava, iam todos e várias outras igrejas também se reuniam com a gente lá. Cadastramos os moradores, entramos na Justiça, botamos advogado. Eles realizaram ações populares para chamar a atenção e serem recompensados, e hoje pode ser que o processo final dê uma indenização (João Thomaz, da Comissão Ambiental Sul, 1/6/2012).

A Igreja Católica permanece, assim, como agente detentor de significativo poder coletivo. Por sua presença política expressiva em Volta Redonda, nas últimas décadas, e por ter se associado a sindicatos de trabalhadores e movimentos sociais nas suas lutas, acumulou recursos políticos para estimular campanhas contestatórias e cobrar soluções às ameaças da poluição ou outras formas de degradação do meio ambiente. O bispo responsável por essa inflexão utiliza as iniciativas formais da Igreja Católica, como a Campanha da Fraternidade, para introduzir e defender esta outra forma de "tomar consciência", abrindo assim a oportunidade de desafiar manifestações do poder corporativo.

Porque tivemos a Campanha da Fraternidade sobre a ecologia e isso contribuiu para uma conscientização maior da sociedade. A gente sabe que essas propostas chegam muito lentamente para o nosso povo. [...] Mas o importante é que estes fatos que começam assim com poucas pessoas vão se ampliando e divulgando. Por exemplo, esse fato lá de Volta Grande [IV]. Tivemos a oportunidade de trazer vários peritos para analisar aquela situação, aquela montanha de escória mesmo debaixo das casas, que com a chuva iam dentro do rio [...]. A CSN é uma força internacional, então sempre esbarrávamos nessa muralha quase assim intransponível (Dom João Messi, 1/6/2012).

A trajetória pessoal de um dos articuladores da Comissão tem a marca dos efeitos da atividade industrial sobre a vida dos empregados e moradores da cidade, nesse caso através das doenças relacionadas às tecnologias de processo empregadas. Já há algum tempo o SMSF vem protestando contra a 
exposição indevida ao benzeno relacionada à leucopenia (Ruiz, Vassalo \& Souza, 1993) e que resultou, inclusive, em uma associação voltada para representar os interesses desse grupo de empregados da CSN afetados pela doença:

Na época em que eu trabalhei para a empresa, trabalhava exatamente nessa área de carboquímicos e fui premiado com a famosa leucopenia. Eu não fui o primeiro. Várias outras pessoas em Volta Redonda tiveram a doença e criou-se uma tal Associação das Pessoas Portadoras da Leucopenia. [...] E o Sindicato dos Metalúrgicos começou a correr atrás disso, começou a entrar na Justiça com o negócio da leucopenia (Délio Guerra, da Comissão Ambiental Sul, 1/6/2012).

A expansão das atividades da CSN nos últimos anos fez Congonhas sentir no seu cotidiano os impactos do aumento de material particulado jogado no ar e dos danos ao manancial de água que abastece a cidade. As agressões ambientais motivaram uma série recente de atos de contestação às implicações da atividade de mineração no território. Trata-se de uma inovação tática ${ }^{19}$ (Tarrow, 2009) no sentido de que este movimento reforçou uma articulação de lideranças populares e ajudou a estruturar coalizões com moradores dos bairros atingidos pelas atividades das empresas mineradoras.

O sindicato dos trabalhadores da mineração (Sindicato Metabase Inconfidentes) se beneficiou dessa conjuntura para reforçar sua capacidade de reivindicação de direitos. Apesar dos novos investimentos da CSN e das outras empresas, estabeleceu-se um quadro de precarização do trabalho, com baixas remunerações (inferiores aos valores pagos em cidades vizinhas), elevados riscos para a saúde (com incidência de problemas respiratórios), e pressão por aumento de produtividade, com o crescimento dos acidentes de trabalho, sobretudo entre trabalhadores terceirizados. No entanto, mesmo sem instrumentos de representação nos locais de trabalho, como "comissão de fábrica" e/ou Comissão Interna de Prevenção de Acidentes (CIPA), o Sindicato Metabase Inconfidentes intensificou suas ações reivindicatórias, inclusive com paralisações, como uma greve de três dias, em 2011. Para as lideranças sindicais, na CSN e na NAMISA são identificadas as piores condições de trabalho do município.

Essa nova articulação política, no entender do presidente do Sindicato Metabase Inconfidentes, ajudou também a recuperar a legitimidade do sindicato como agente de reivindicação de direitos, depois de uma aparente perda de status do operário da $\mathrm{CSN}^{20}$ e contribuiu para redimensionar a relação do sindicato com a cidade.

Aqui em Congonhas, eu acho que o Sindicato deve ser a quarta ou quinta instituição [...]. Têm aí os três poderes, tem a Igreja e depois temos nós, ou seja, temos um peso na cidade [...]. O Sindicato, na verdade, em outros momentos, sob outras direções, elegeu deputados, elegeu vereadores, [...] ajudou a eleger prefeitos. Mas a nossa polí- 
tica é de tentar se aproximar dos movimentos populares e tentar construir pautas comuns (Jerônimo Castro, Presidente do Sindicato Metabase Inconfidentes, 3/8/2012).

De outro lado, a questão das nascentes de água localizadas no bairro Pires, de Congonhas, se transformou em mobilização da comunidade local e de outros agentes políticos contra o cerco da CSN e das outras quatro mineradoras de ferro do município. A contestação social e o confronto político em torno dos potenciais danos ambientais e dos problemas de saúde pública, de um lado, assim como pela restrição ao acesso à água, foi o bastante para, com o auxílio da Igreja Católica, se constituir um movimento de questionamento à ação das empresas que se manifestou com reclamações e demandas junto à administração pública -, mas também se expressou por vias não institucionalizadas.

Abriram uma estrada que danificou os mananciais. Esse é o caso mais relevante de dano ambiental aqui dentro de Congonhas. Três mil habitantes sem água por três meses, barro dentro de casa, chuveiro explodindo porque passava minério e fechava os contatos. [...] Nós notamos que havia uma moça religiosa que comandava a pastoral. Essa moça tinha [...] contato com o pároco que atende eles lá [...]. O padre nos chamou e explicamos o que estava acontecendo. "Isso é muito grave, vou começar a falar disso na missa". Aí, com o padre falando na missa, [...] lá no Pires, e aqui em Congonhas, o negócio começou a ganhar vulto. [...] O pessoal, depois de algum tempo sem água, com a água poluída por barro, juntou uns dois, três ônibus e veio aqui na Prefeitura (Representante do Grupo Rede Congonhas, 31/7/2012).

O grupo de reflexão da Igreja Católica coordenou o processo de organização da comunidade, e articulou manifestações e mobilizações nas nascentes, participou do Grito dos Excluídos e ganhou aliados no Ministério Público. Todo esse movimento atingiu seu ápice em uma situação de confronto político, com a retomada e a limpeza de uma nascente remanescente. Nas palavras do principal líder comunitário de Pires:

Vamos limpar. Sete horas da manhã, todo mundo na nascente. Fulano vai arrumar um carro e vai buscar comida, o outro grupo vai arrumar refrigerante, porque não tem água... Se vier polícia, não deixa. Se for o caso, pega pau, ali tem muito pau, mete o cacete. Porque não podemos ficar sem água. E o pessoal foi entrando na nossa [...]. E assim se fez. Aí teve polícia, teve a polícia militar, teve a Secretaria do Meio Ambiente, teve Ministério Público, teve todo mundo. Teve COPASA. [...] Então, a gente foi aprendendo como que a Justiça também teme o cidadão. A gente não sabia disso [...]. A comunidade se uniu e se fortaleceu e hoje tudo o que acontece ou o que vai acontecer, eles ligam pra gente (Líder Comunitário do Bairro Pires, 4/8/2012).

As manifestações da comunidade no Pires tiveram grande repercussão junto à Prefeitura Municipal e à Câmara de Vereadores. E, mais significativo em termos de ação coletiva de confronto político, resultaram em mobilizações contra a ação e interferência das mineradoras na vida local. A Arquidiocese de Mariana (MG), através do seu trabalho pastoral, ajudou a estruturar conselhos comunitários e grupos de discussão e reflexão política, de onde surgiram lideranças (em geral, mulheres) com capacidade de arregimentação 
para protestos e reivindicações. Outras entidades, como a União das Associações de Moradores (UNACON) e setores da comunidade acadêmica, além do Grupo Rede Congonhas, também se juntaram às mobilizações para contribuir na elaboração de projetos alternativos àqueles implantados no município.

O Grupo Rede Congonhas foi formado no início por umas quatro ou cinco pessoas. Somos eu, que sou bacharel em Direito [...], alguns engenheiros, técnicos, mas a gente forma um coletivo informal [...] para contribuir pra melhorar a cidade. Chegamos a fazer propostas que foram formalizadas junto à administração pública, mas não houve assim uma repercussão. [...] A gente fez sempre assim, primando por atuar mais na via administrativa [...] porque nós não temos [...] condições de "judicializar" questões dessa monta, [...] mas sempre provocando o poder público [...], expondo as questões. [...] A gente tem [...] uma boa credibilidade com alguns órgãos de imprensa e até com a comunidade acadêmica. Mas o Grupo Rede Congonhas não tem rotina, não tem formalidade, [...] não tem uma estrutura. (Representante do Grupo Rede Congonhas, $31 / 7 / 2012)$.

Criado em 2003, o Grupo Rede Congonhas se assemelha à Comissão Ambiental Sul por também agregar segmentos da classe média e indivíduos- chave dotados de conhecimento técnico, em diálogo com a comunidade acadêmica. Por sua vez, sua atuação propositiva, nos marcos da expansão econômica do município, é subsidiária à dimensão elementar de publicização do conflito socioambiental como contestação às ações da CSN e do poder público local - através dos vínculos com grupos sociais afetados diretamente e de ações midiáticas.

No caso de Volta Redonda, sob condições de retração econômica, um declínio da capacidade agregativa do tradicional SMSF, permitiu que a "questão pública do meio ambiente", passasse a ser o elaborador de novas subjetividades e identidades. Beynon (1999), em sua análise pioneira sobre a resistência à expansão das minas de carvão a céu aberto do Reino Unido, demonstra que grupos de protesto em áreas de conflito socioambiental tenderam a incorporar setores escolarizados da classe média e sua repercussão no seio das comunidades mineiras se deveu também à redução da atividade sindical por causa do desemprego, favorecendo a adesão dos trabalhadores à causa ambiental.

Em Congonhas, o movimento sindical dos trabalhadores da mineração teve pouca participação no debate sobre a privatização da CSN. Mas, no decorrer dos últimos anos, com a intensificação da atividade mineradora, se fortaleceu devido principalmente ao aumento do número de empregados e a valorização da categoria no tocante aos novos planos de desenvolvimento da empresa. Por essa razão, pode-se dizer que, ao contrário de Volta Redonda, na arena política local o sindicato dos mineiros acumulou força de reivindicação de modo a interferir nos projetos de crescimento da empresa.

Como marco dessa nova fase de disputas políticas em Congonhas está a divergência acerca da exploração da Serra de Casa de Pedra, envolvendo 
Prefeitura, Câmara de Vereadores, Ministério Público, CSN e entidades de sociedade civil que defendem o seu tombamento. A expansão da mina Casa de Pedra implica a oferta de benefícios por parte da CSN (como a promessa de uma usina siderúrgica), em troca de vantagens e apoio político, por parte de grupos de interesse local, mas traz também custos sociais e ambientais ao conjunto da sociedade. O cerne da argumentação contestatória quanto à expansão dos projetos extrativos de ferro diz respeito à alteração paisagística e ao impacto sobre os recursos hídricos potencialmente provocados.

Em 2010, o presidente da CSN, Benjamin Steinbruch, anunciou um projeto de expansão da empresa que opera na mina Casa de Pedra, em Congonhas, de R 12 bilhões, mesmo ano em que a Câmara local realizou audiência pública para discutir os limites do tombamento da serra, aprovado em Lei Municipal em 2007. Na ocasião, a população da cidade temia que o projeto da CSN pudesse vir a comprometer o aspecto visual dos profetas do Aleijadinho, que ficam situados no Santuário de Bom Jesus do Matosinhos, considerado Patrimônio Cultural da Humanidade pela Unesco (Durão, 2012).

Em 5 de setembro de 2009, o Ministério Público de Minas Gerais (MPMG), emitiu parecer de recomendação pela preservação do Morro do Engenho, na Serra Casa de Pedra, à Câmara Municipal de Congonhas (Bacias de Minas, 2011). O MPMG considera a Serra Casa de Pedra parte integrante do "Conjunto Escultórico do Adro da Basílica de Bom Jesus de Matozinhos", reconhecido pela Unesco como Patrimônio Cultural da Humanidade desde 1985, e enfatiza sua relevância para a preservação do equilíbrio ecossistêmico e para o abastecimento hídrico de Congonhas. ${ }^{21}$ Sua recomendação final concorda com a delimitação, mínima e potencialmente expansível, do polígono de tombamento proposto pelo Projeto de Lei $n^{\circ}$ 027/2008, o que inviabilizaria o projeto de expansão da CSN.

Nesta arena, a disputa política opõe dois blocos de interesse: de um lado, os poderes executivo e legislativo, em seus níveis estadual e municipal, e a CSN (a empresa e o Governo do Estado de Minas Gerais possuem um "protocolo de intenções de investimento" acordado de R 16 bilhões (Exame, 2012)); de outro, os segmentos mobilizados da sociedade civil de Congonhas, tendo à frente o Grupo Rede Congonhas, apoiado pelo sindicato dos mineiros, grupos de afetados pela mineração e parlamentares locais cuja ação política é centrada na pauta ambiental.

Após um debate acirrado, que perdurou por todo o ano de 2012, e ameaças de fechamento da NAMISA pela CSN, a Câmara de Vereadores de Congonhas aprovou um projeto de lei de tombamento parcial da Serra de Casa de Pedra, determinando a preservação de $85 \%$ do perímetro da serra e liberando $15 \%$ para estudos geológicos e futura expansão do grupo CSN, justamente a fatia do Morro do Engenho e o do Pilar onde estão as minas Casa de Pedra (da CSN) e outras da NAMISA. 
O projeto de lei aprovado em segundo turno fixa condicionantes a serem cumpridos pela empresa. A futura lei dá um prazo de três anos para o grupo CSN fazer estudos geológicos para avaliar o potencial mineral da região e apresentar ao município um plano sustentável de utilização da área para seu plano de ampliar a exploração mineral no Morro do Engenho. [...] Anderson Cabido, prefeito de Congonhas (sem partido), não vê possibilidade de a cidade perder o título de "patrimônio cultural da humanidade", como vem sendo ventilado por opositores da proposta vencedora. O projeto de lei seguiu ontem para sanção do prefeito (Durão, 2012).

Os processos de questionamento da ação econômica em Congonhas e Volta Redonda apresentam uma dinâmica reativa à evolução da rede de produção da CSN. Entretanto, a recomposição das arenas territoriais impelida pela empresa tem produzido formas de contestação social e confronto político que, embora incipientes, integram, de forma inovadora, agentes, como sindicatos de trabalhadores e movimentos sociais, tradicionalmente cindidos em torno das questões trabalhista e ambiental. Mais importante, essas questões vêm convergindo em Congonhas e Volta Redonda, produzindo formas de regulação do comportamento da CSN - assim como de legitimidade política, disputando a construção da agenda pública nos territórios - extremamente relevantes para o seu futuro na rede de produção minero-siderúrgica global.

\section{CONCLUSÃO}

A análise da ação empresarial da Companhia Siderúrgica Nacional, em Volta Redonda e Congonhas, como parte de uma rede global de produção mínero-siderúrgica, permitiu destacar a dimensão territorial como elemento aglutinador da interseção de escalas analíticas e de ação política e social. Nesse sentido, as formas de ação coletiva contestatórias e confrontacionais nos territórios escolhidos, identificadas algumas das debilidades estruturais macrossetoriais e corporativas, repercutiram em termos de acúmulo e mobilização de formas de poder institucional e, em especial, de poder coletivo capazes de, potencialmente, condicionar a ação econômica.

Especificamente, a natureza altamente intensiva da exploração de bens naturais e do trabalho na rede global de produção mínero-siderúrgica abre um flanco de contestação social e confronto político próprio da perspectiva das lutas em torno do questionamento e controle de grandes projetos de investimento e de grandes empresas no território, com impactos na sua capacidade de criação, ampliação e captura de valor.

Os casos do Fórum Demissão Zero e da Comissão Ambiental Sul, em Volta Redonda, e do Grupo Rede Congonhas demonstram certa evolução das formas de ação coletiva confrontacional, quando mediante novas mobilizações políticas fazem interagir a questão do trabalho, através dos operários e seus agentes de representação institucional; e a questão ambiental, por meio dos 
cidadãos e das organizações e movimentos ambientalistas. As condições específicas sob as quais tais estratégias não econômicas, embora economicamente relevantes, são configuradas, depende da integração das dimensões econômica, política e social e das escalas de ação global, nacional e local (para ficarmos apenas em três).

A estratégia corporativa em rede da CSN, de privilegiar e incorporar a exploração mineral de acordo com a configuração contemporânea da rede global de produção mínero-siderúrgica é condição necessária para sua competitividade no mercado. No entanto, tal estratégia é contestada e confrontada a partir do poder coletivo enraizado no território - poder esse que disputa a adesão dos agentes políticos e de seu poder institucional -, sendo efetivamente influenciada por disputas acerca da legalidade e legitimidade de projetos; processos e produtos; espacialidades extrativas, logísticas e produtivas etc. Essencialmente, atrasos de cronogramas de obras civis e de engenharia, acordos de ajustamento de conduta, pagamentos indenizatórios, entre outras formas de reconhecimento do poder coletivo, embora marginais, afetam as capacidades relativas de promoção da reprodução ampliada de capital, influenciando, no limite, "destinos" corporativos.

A reorientação extrativista estratégica da CSN no território de Congonhas - com perda relativa de importância da siderurgia e de Volta Redonda, é centrada na adesão de poderes institucionais nas escalas local, estadual e nacional - ignorando momentaneamente seus nós territoriais logísticos e internacionais. Entretanto, a contestação social e o confronto político em ambos os territórios vêm refletindo capacidades locais de enraizamento territorial antigas e novas, influenciando de modo complementar tanto a expansão quanto a contração dos investimentos da Companhia. Desse modo, a ação coletiva em torno dos destinos do ambiente e do trabalho em ambos os territórios aponta, potencialmente, para mudanças concretas na arena constituída em torno da rede de produção da CSN; mudanças dirigidas ao condicionamento da ação econômica e da sociodeterminação territorial. 
José Ricardo Ramalho é professor titular do Departamento de Sociologia e do Programa de Pós-Graduação em Sociologia e Antropologia (PPGSA) da Universidade Federal do Rio de Janeiro (UFRJ), e pesquisador do Conselho Nacional de Desenvolvimento Científico e Tecnológico (CNPq). Atua principalmente na área sociologia do trabalho, desenvolvendo pesquisas, entre outros temas, sobre relações de trabalho na indústria; trabalho, emprego e desenvolvimento econômico regional e local. Recentemente coorganizou a coletânea Desenvolvimento, trabalho e cidadania: Baixada e Sul fluminense, com Alexandre Fortes (2012).

Rodrigo Salles Pereira dos Santos é professor adjunto da Universidade Federal de Juiz de Fora (UFJF) e faz parte do Programa de Pós-Graduação em Serviço Social (PPGSS) dessa instituição. Doutor em Ciências Humanas - Sociologia, pela Universidade Federal do Rio de Janeiro (UFRJ), atua na área de sociologia econômica e do desenvolvimento, pesquisando os seguintes temas: desenvolvimento econômico e regional, redes de produção globais, mineração e indústria siderúrgica. É autor, entre outros, de "Redes de Produção Globais (RPGs). Contribuições conceituais para a pesquisa em ciências sociais" (2011).

Raphael Jonathas da Costa Lima é professor adjunto da Universidade Federal Fluminense (UFF), faz parte do Programa de Pós-Graduação em Tecnologia Ambiental (PGTA) e do Programa de Pós-Graduação em Administração (PPGA) da mesma instituição. Doutor em Ciências Humanas pela Universidade Federal do Rio de Janeiro (UFRJ), desenvolve pesquisa sobre os seguintes temas: movimentos sociais, sindicato e política, desenvolvimento regional, trabalho, siderurgia e indústria automobilística. É autor, entre outros, "Estratégias integradas de regeneração em regiões industriais: uma aproximação com a conjuntura pós-década de 1990 no Sul Fluminense" (2012). 


\section{NOTAS}

1 Este texto se beneficia de resultados parciais de projetos de pesquisa, apoiados pelo Conselho Nacional de Desenvolvimento Científico e Tecnológico (CNPq); pela Fundação de Amparo à Pesquisa do Estado do Rio de Janeiro (Faperj), através do Programa Cientistas do Nosso Estado e do programa Auxílio Instalação (INST) 2012; e pela Universidade Federal de Juiz de Fora, através do Programa de Apoio à Instalação de Doutores/UFJF-2012-2013. Os autores são gratos à mestranda Cristiane D. Ribeiro (PPGSS/UFJF) e aos bolsistas de Iniciação Científica Ana Luiza Q. Freitas e Gabriela F. Fernandez (UFRJ); Marília M. Schocair (UFF); e Raphael V. Leitão (UFJF), pelo apoio na realização do trabalho de campo em Volta Redonda e Congonhas.

2 A expressão original em inglês é global production networks.

3 Santos (2011) usa o exemplo do município de São Luís (MA) para demonstrar essa possibilidade. Em 2004, um projeto siderúrgico de grande porte - capitaneado pela empresa Vale S. A. e pela chinesa Baosteel Group Co. - explicitou o confronto entre as formas corporativa, institucional e coletiva do poder. O projeto sofreu contestação social por um conjunto de movimentos sociais - dentre os mais notáveis, o Movimento Reage São Luís e o Fórum Carajás que se empenhou na desconstrução do discurso desenvolvimentista das elites políticas e econômicas locais e estaduais (Lima, 2009), de modo que a referida decisão de investimento fosse avaliada também moralmente. Concretamente, a imagem construída de um evento futuro - a instalação de um parque siderúrgico - alterou as capacidades relativas de ação coletiva dos envolvidos nas disputas em torno da legalidade e legitimidade do projeto. A ação de grupos de interesse (por exemplo, a classe média urbana de São Luís) e de organizações sociais (como o Movimento Reage São Luís) que a representam, em associação com camadas populares potencialmente impactadas, acabou por transformar o risco potencial em uma imagem socialmente penetrante apta a produzir efeitos práticos em termos de bloqueio da agência de agentes "poderosos" - isto é, dotados de poder corporativo, como a Baosteel e a Vale. Em outros termos, os movimentos sociais, isto é, os agentes economicamente relevantes, 
mediando e construindo um projeto desenvolvimentistapreservacionista, transmutaram uma cosmovisão urbana em interesse coletivo. Ao fazê-lo, foram capazes de atrair indivíduos e organizações políticos relevantes, particularmente em âmbito estadual, em uma ampla coalizão. O resultado foi o bloqueio de uma decisão de investimento. $\mathrm{O}$ exercício do poder coletivo adquiriu preeminência, nesse caso, sobre o poder institucional, e sobrepôs-se às estratégias dos agentes econômicos (corporativos).

4 Para investigar decisões de implante, expansão e investimento minerais e siderúrgicos, como no caso da CSN, a noção de "grandes projetos de investimento" - em geral concentrados em redes de atividades industriais extrativas e de transformação e caracterizados por amplo impacto ambiental e socioeconômico (Vainer, 1990: 179-180) -, pode também ser utilizada como instrumento de análise. A expansão da mina Casa de Pedra em Congonhas, por exemplo, explicita a dimensão específica na qual as estratégias corporativas e a ação coletiva confrontacional emergente interagem de forma conflituosa, como locus decisivo para um estudo centrado no território.

5 Um das dimensões relevantes do contentious politics project é o seu caráter de arena, na qual se defrontam publicamente não apenas os movimentos sociais, mas outros tipos de agentes e instituições, incluindo os operadores estatais (Tarrow, 2011: 30-31).

6 Uma "rede global de produção", segundo Henderson et al. (2011: 153) é definida, primeiramente, como "[...] o nexo de funções e operações interligadas através das quais bens e serviços são produzidos, distribuídos e consumidos - [...] [e são] tanto organizacionalmente mais complexas quanto cada vez mais globais em sua extensão geográfica. Essas redes não apenas integram firmas (e partes de firmas) em estruturas que obscurecem fronteiras organizacionais tradicionais - por meio do desenvolvimento de diversas formas de relações de equidade e não-equidade -, mas também integram economias nacionais (ou partes dessas economias) de formas que possuem implicações colossais para seu bem-estar. Ao mesmo tempo, a natureza e a articulação precisas das redes de produção centradas na firma são profundamente influen- 
ciadas pelos contextos sociopolíticos dentro dos quais elas estão enraizadas".

7 Utilizamos duas acepções do conceito de "redes globais de produção" no texto. A primeira se refere a uma estrutura de mercado, abrangendo um setor e/ou subssetores econômicos e centrada nas corporações transnacionais líderes. Nesse sentido, a rede de produção é inerentemente global em seus fluxos de insumos, mercadorias e resíduos. A segunda definição é determinada pela estratégia corporativa de uma firma líder, a CSN, mas realça os diferentes agentes e poderes que a influenciam nos territórios de Volta Redonda e Congonhas, podendo ser definida em diferentes escalas analíticas.

8 Em 2010, a produção brasileira de aço bruto alcançou 32,9 Mtpa.

9 Entre os principais acionistas, estavam a Docenave $(9,4 \%)$, o Bamerindus (9,1\%), o Bradesco (7,7\%), o Grupo Vicunha $(9,2 \%)$, um Clube de Investimentos composto por funcionários $(11,9 \%)$, outros bancos $(18,8 \%)$ e alguns fundos de pensão $(2,7 \%)$.

10 Com $31 \mathrm{~km}^{2}$ (Minérios \& Minerales, 2009), projeta-se a expansão de capacidade instalada da mina Casa de Pedra por parte da CSN, até 2015, das atuais 20 Mtpa. para 89 Mtpa. (expansível até $100 \mathrm{Mtpa}$.) (Alerigi Jr, 2012).

11 A CSN detém $60 \%$ do capital e os outros $40 \%$ pertencem a um consórcio formado por usinas siderúrgicas asiáticas (CADE, 2008).

12 A cidade foi construída, a partir da década de 1940, sob o modelo de "fábrica com vila operária" e dentro da perspectiva varguista de transformar a empresa em um espaço formador de um "trabalhador brasileiro" (ver Pereira, 2012; Lima, 2010; Piquet, 1998; Morel, 1989, entre outros).

13 Estima-se que 65\% da arrecadação de Congonhas estejam ligados à mineração, o que equivale a $\mathrm{R} \$ 300$ milhões.

14 Em 1997, a Associação Comercial, Industrial e Agropastoril de Volta Redonda (ACIAP-VR), representando o setor empresarial de Volta Redonda, organizou uma série de seminários para discutir iniciativas de desenvolvimento sustentável e de geração de emprego e renda. A mobilização, que inclusive contou com a participação de diversos de- 
fensores da privatização, ficou conhecida como Movimento Vamos Repensar Volta Redonda (Lima, 2012; Baptista, 2008).

15 O conceito de estrutura de oportunidades e restrições políticas diz respeito a ambientes ou contextos políticos de interação de autoridades e desafiantes relativamente estabilizados. Nesse sentido, elementos disruptivos significativos - como a entrada de novos agentes, inovações táticas e alterações organizacionais expressivas etc. - tenderiam a impelir mudanças na estrutura, configurando dimensões consistentes de encorajamento e desencorajamento à ação coletiva confrontacional (Tarrow, 2009: 38-39).

16 Para uma descrição mais detalhada desse período da história do sindicato, ver Pereira (2012); Dias (2010); Graciolli (2007; 1997).

17 Do então prefeito Paulo César Baltazar.

18 A Agenda 21 foi uma derivação do Comitê de Qualidade de Vida, constituído dentro do "Movimento Vamos Repensar Volta Redonda" (Lima, 2010).

19 A noção de inovação tática faz referência às variações incrementais de ações, performances e rotinas criadas, adicionadas e/ou replicadas interativamente no âmbito de um repertório de ação coletiva, mas que se projetam sobre ele de forma a transformá-lo no longo prazo (Tarrow, 2009). No caso específico de Congonhas, a contestação e o confronto se basearam, em grande medida, na configuração de um símbolo coletivo (a Serra Casa de Pedra como patrimônio cultural), no estreitamento de conexões locais (entre atingidos pela mineração, movimento ambientalis ta e sindicato de trabalhadores) e na introdução de novas performances públicas (como o Grito dos Excluídos).

20 “....] Vinte anos atrás, se o cara fosse da CSN, era meio que uma aristocracia operária [...], um operário tinha uma vida de classe média, tanto que, se você pegar os antigos funcionários da CSN, uma boa parte deles é casada com famílias importantes da cidade, tem casas em lugares bem localizados [...]. A CSN estatal não era o paraíso, mas era mais ou menos como a Petrobras hoje, entendeu? (Jerônimo Castro, presidente do Sindicato Metabase Inconfidentes, 03/08/2012).

21 “[...] destacando-se que se encontram outorgadas à Copasa, na área de Serra Casa de Pedra, 29 pontos de cap- 
tação para fins de abastecimento da população" (Bacias de Minas, 2011).

\section{REFERÊNCIAS BIBLIOGRÁFICAS}

Alonso, Angela. (2012). Repertório segundo Charles Tilly: história de um conceito. Sociologia \& Antropologia, 2/3, p. 21-41. Alerigi Jr., Alberto. (2012). MG volta a discutir mina da CSN na próxima semana. Disponível em <http://br.reuters.com/ article/businessNews/idBRSPE81007C20120201?sp=true>. Acesso em 14 fev. 2012.

Bacias de Minas. (2011). MPE recomenda proteção da Serra Casa de Pedra, em Congonhas. Disponível em <http:// blogs.mp.mg.gov.br/baciasdeminas/2011/05/09/mperecomenda-protecao-da-serra-casa-de-pedra-em-congonhas/>. Acesso em 14 fev. 2012.

Baptista, Letícia B. (2008). Agenda 21, uma experiência em Volta Redonda. Dissertação de Mestrado. PPGAU/Universidade Federal Fluminense.

Beynon, Huw. (1999). Protesto ambiental e mudança social no Reino Unido. Mana, 5/1, p. 7-28.

Braga, Juliana. (2002). População reage contra fechamento da Cicuta: atitude da CSN é condenada por associações de moradores, prefeito e vereadores. Nova trilha é desprezada. Foco Regional, 88, 9-15 dez.

Bringel, Breno. (2012). Com, contra e para além de Charles Tilly: mudanças teóricas no estudo das ações coletivas e dos movimentos sociais. Sociologia \& Antropologia, 2/3, p. 43-67.

CADE. (2009). Ato de Concentração n. 08012.011002/200862, 27 jan. Disponível em <http://www.cade.gov.br/temp/ t82201311235736.pdf>. Acesso em 24 fev. 2012.

Costa, Célia M. L.; Pandolfi, Dulce C. \& Serbin, Kenneth (orgs.). (2001). O bispo de Volta Redonda: memórias de Dom Waldyr Calheiros. Rio de Janeiro: Ed. FGV.

Cox, Kevin R. \& Mair, Andrew. (1988). Locality and community in the politics of local economic development. Annals of the Association of American Geographers, 78/2, p. 307-325. Dias, Sabrina de Oliveira Moura. (2010). Dentro da usina, mas fora da família: trabalhadores e terceirização na Companhia 
Siderúrgica Nacional (CSN). Dissertação de Mestrado. PPGSA/ Universidade Federal do Rio de Janeiro.

De Sardan, Jean Pierre Olivier. (2005). Anthropology and development: understanding contemporary social change. Londres/Nova York: Zed Books.

Durão, Vera Saavedra. (2012). Congonhas preserva mina da CSN. Valor Econômico, 20 dez. Disponível em <http:// clippingmp.planejamento.gov.br/cadastros/noticias/2012/12/20/congonhas-preserva-mina-da-csn>. Acesso em 21 dez. 2012.

Exame. (2012). Futuro de projeto da CSN em MG divide Congonhas, 27 fev. Disponível em <http://exame.abril.com. $\mathrm{br} /$ economia/meio-ambientee-energia/noticias/futuro-de-projeto-da-csn-em-mg-divide-congonhas-3? page =1\&slug name $=$ futuro - de - projeto - da - csn-em-mg-divide - congo nhas-3>. Acesso em 28 mar. 2012.

Graciolli, Edilson José. (2007). Privatização da CSN: da luta de classes à parceria. São Paulo: Expressão Popular.

Graciolli, Edilson José. (1997). Um caldeirão chamado CSN: resistência operária e violência militar na greve em 1988. Uberlândia: Ed. UFU.

Henderson, Jeffrey et al. (2011). Redes de Produção Globais e a análise do desenvolvimento econômico. Revista Pós -Ciências Sociais, 8/15, p. 143-170.

Hess, Martin. Global production networks: dealing with diversity. (2004). In: Haak, René \& Tachiki, Dennis (orgs.). Regional strategies in a global economy: multinational corporations in East Asia. Munique: Iudicium, p. 31-52.

Hommel, Thierry; Godard, Olivier. (2005). Contestação social e estratégias de desenvolvimento industrial: aplicação do modelo da gestão contestável à produção industrial de OGM. In: Varella, Marcelo Dias \& Barros-Platiau, Ana Flávia (orgs.). Organismos geneticamente modificados. Belo Horizonte: Del Rey.

Leite Lopes, José Sérgio et al. (orgs.). (2004). A ambientalização dos conflitos sociais: participação e controle público da poluição industrial. Rio de Janeiro: Relume Dumará.

Lima, Raphael Jonathas da Costa. (2012). Articulação e reorganização sociopolítica em Volta Redonda no pós- 
-privatização da Companhia Siderúrgica Nacional. In: Ramalho, José Ricardo \& Fortes, Alexandre (orgs.). Desenvolvimento, trabalho e cidadania: Baixada e Sul fluminense. Rio de Janeiro: 7 Letras, p. 203-224.

Lima, Raphael Jonathas da Costa. (2010). A “Reinvenção" de uma cidade industrial: Volta Redonda e o pós-privatização da Companhia Siderúrgica Nacional. Tese de Doutorado. PPGSA/ Universidade Federal do Rio de Janeiro.

Lima, Raphael Jonathas da Costa. (2009). Movimentos sociais, desenvolvimento e capital social: a experiência do Reage São Luís. In: Sant’Ana Jr., Horácio et al. (orgs.). Ecos dos conflitos sócio-ambientais: a RESEX de Tauá-Mirim. São Luís: Ed. UFMA, p. 225-253.

Milanez, Bruno. (2011). Grandes minas em Congonhas (MG), mais do mesmo? In: Fernandes, Francisco R. C.; Enriquez, Maria Amélia R. S. \& Alamino, Renata C. J. (orgs.). Recursos minerais \& sustentabilidade territorial. Rio de Janeiro: CETEM/ MCTI, p. 199-228 (vol. I).

Minérios \& Minerales. (2009). 200 maiores minas brasileiras. Minérios \& Minerales, 316, 20 jun.

Morel, Regina L. (1989). A ferro e fogo. Construção e crise da família siderúrgica: o caso de Volta Redonda (1941-1968). Tese de Doutorado. PPGS/Universidade de São Paulo.

Pereira, Sérgio E. M. (2012). Sindicalismo e privatização: o caso da Companhia Siderúrgica Nacional. São Luís: Ed. UFMA. Piquet, Rosélia. (1998). Cidade-empresa: presença na paisagem urbana brasileira. Rio de Janeiro: Zahar.

Ramalho, José Ricardo. (2012). Fórum Demissão Zero: crise e ação coletiva no Sul Fluminense. In: Ramalho, José Ricardo \& Fortes, Alexandre (orgs.). Desenvolvimento, trabalho e cidadania: Baixada e Sul fluminense. Rio de Janeiro: 7 Letras, p. 225-246.

Ramalho, José Ricardo. (2005). Novas conjunturas industriais e participação local em estratégias de desenvolvimento. Dados, 48/3, p. 491-523.

Ramalho, José Ricardo \& Carneiro, Marcelo Sampaio. (2013). Ação sindical, contestação política e siderurgia na Amazônia brasileira. Novos Cadernos NAEA (no prelo). 
Ruiz, Milton Artur; Vassallo, José \& Souza, Cármino Antonio de. (1993). Alterações hematológicas em pacientes expostos cronicamente ao benzeno. Revista Saúde Pública, 27/2, p. 145-151.

Santos, Rodrigo Salles Pereira dos. (2010). A forja de Vulcano: siderurgia e desenvolvimento na Amazônia Oriental e no Rio de Janeiro. Tese de Doutorado. PPGSA/Universidade Federal do Rio de Janeiro.

Santos, Rodrigo Salles Pereira dos. (2012). Redes de Produção Globais, transformação estrutural e crítica/contestação social: a TKCSA em Itaguaí, RJ. In: Ramalho, José Ricardo \& Fortes, Alexandre (orgs.). Desenvolvimento, trabalho e cidadania: Baixada e Sul fluminense. Rio de Janeiro: 7 Letras, p. 43-76. Santos, Rodrigo Salles Pereira dos. (2011). Introdução às Redes de Produção Globais (RPGs): contribuições para a pesquisa em Ciências Sociais. Revista Pós Ciências Sociais, 8/15, p. 127-142. Tarrow, Sidney. (2011). Global, conventional and warring movements and the suppression of contention. Themes in contentious politics research. Política \& Sociedade, 10/18, p. 25-49.

Tarrow, Sidney. (2009). O poder em movimento: movimentos sociais e confronto político. Petrópolis: Vozes.

Tilly, Charles M. (1979). Repertoires of contention in America and Britain: 1750-1820. In: Zald, Mayer N. \& Mccarthy, John (orgs.). The dynamics of social movements: Resource mobilization, social control, and tactics. Cambridge, MA: Winthrop, p. 126-155

Tilly, Charles M. (1978). From mobilization to revolution. Nova York: McGraw-Hill.

Tilly, Charles M. \& Tarrow, Sidney. (2008). Politique(s) du conflit. De la grève à la révolution. Paris: Les Presses de Sciences Po.

Tilly, Charles M. \& Tarrow, Sidney. (2007). Contentious politics. Londres: Paradigm Publishers.

Vainer, Carlos B. (1990). Grandes projetos e organização territorial: os avatares do planejamento regional. In: Margulis, Sergio (org.) Meio ambiente: aspectos técnicos e econômicos. Rio de Janeiro: IPEA, p. 179-211.

Weber, Max. (2000). Economia e sociedade: fundamentos da sociologia compreensiva. 3. ed. Brasília: Ed. UnB (vol. 1). 
200

\section{ESTRATÉGIAS DE DESENVOLVIMENTO INDUSTRIAL E DINÂMICAS TERRITORIAIS DE CONTESTAÇÃO SOCIAL E CONFRONTO POLÍTICO}

Resumo

$\mathrm{O}$ artigo discute o conflito socioambiental estabelecido na interação entre o desenvolvimento de estratégias industriais em rede, através da Companhia Siderúrgica Nacional (CSN), e formas emergentes de contestação social e confronto político nas localidades siderúrgicas e de extração mineral de Volta Redonda (RJ) e Congonhas (MG). $O$ argumento central enfatiza a importância dessas formas de enraizamento social como condicionantes da ação econômica, considerando principalmente a natureza inovadora da integração de questões do trabalho e do meio ambiente nos territórios pesquisados.

\section{STRATEGIES OF INDUSTRIAL DEVELOPMENT, DYNAMICS OF TERRITORIAL CONTESTATION AND POLITICAL CONFRONTATION}

\footnotetext{
Abstract

This article discusses the socio-environmental conflict ensuing the association between the development of industrial networks' strategies by the CSN Group (Companhia Siderúrgica Nacional) and the emerging forms of social contestation and contentious politics in the steel and mining localities of Volta Redonda (RJ) and Congonhas (MG). The main argument emphasizes the importance of these forms of social embeddedness in conditioning economic action, considering mostly the innovative nature of integrating issues of environment and labor in the investigated territories.
}

Palavras-chave

Confronto político;

Localidades siderúrgicas e mineiras; Estratégias de desenvolvimento industrial; Redes de produção; Companhia Siderúrgica Nacional.

\section{Keywords}

Contentious politics; Mining and steel localities; Industrial development strategies; Production networks; CSN Group. 